\title{
Use of Laser-Capture Microdissection for the Identification of Marker Genes for the Ventromedial Hypothalamic Nucleus
}

\author{
Jeremy P. Segal, ${ }^{1}$ Nancy R. Stallings, ${ }^{2}$ Charlotte E. Lee, ${ }^{3}$ Liping Zhao, ${ }^{2}$ Nicholas Socci, ${ }^{5}$ Agnes Viale, ${ }^{4}$ Thomas M. Harris, ${ }^{6}$ \\ Marcelo B. Soares, ${ }^{7}$ Geoffrey Childs, ${ }^{6}$ Joel K. Elmquist, ${ }^{3}$ Keith L. Parker, ${ }^{2}$ and Jeffrey M. Friedman ${ }^{1}$ \\ ${ }^{1}$ The Rockefeller University, New York, New York 10021, ${ }^{2}$ University of Texas Southwestern Medical Center at Dallas, Dallas, Texas 75390-8857, ${ }^{3}$ Beth Israel \\ Deaconess Medical Center, Boston, Massachusetts 02215, ${ }^{4}$ Department of Molecular Biology, ${ }^{5}$ Memorial Sloan-Kettering Cancer Center, New York, New \\ York 10021, ${ }^{6}$ Albert Einstein College of Medicine, Bronx, New York 10461, and 7 Department of Pediatrics, University of Iowa Health Care, Iowa City, Iowa \\ 52242
}

The ventromedial hypothalamic nucleus (VMH) plays an important role in the control of feeding and energy homeostasis. In contrast to other hypothalamic nuclei that are also known to regulate energy balance, there is a paucity of nucleus-specific marker genes for the VMH, limiting the application of molecular approaches for analyzing VMH information processing, function, and circuitry. Here, we report the use of laser-capture microdissection to isolate a set of cDNAs that are enriched in the VMH relative to two adjacent hypothalamic nuclei, the arcuate and dorsomedial hypothalamus. The relative expression levels of nine of the 12 most robustly expressed VMH-enriched genes were confirmed by real-time PCR analysis using separate RNAs from these three nuclei. Three of these VMH-enriched genes were further characterized by in situ hybridization histochemistry, including pituitary adenylate cyclase activating polypeptide, cerebellin 1 , and an expressed sequence tag named $L B H 2$. Finally, to test whether some of these genes were coordinately regulated, we monitored their expression in steroidogenic factor 1 (SF-1) knock-out mice. SF-1 is a transcription factor that controls the development of the VMH. The RNA levels for four of these genes were reduced in these knock-out animals, further suggesting that they are direct or indirect targets of this orphan nuclear receptor. The VMH-enriched genes identified here provide a basis for a functional analysis of VMH neuronal subpopulations via the use of bacterial artificial chromosome transgenics and related technologies. These results also demonstrate the utility of laser-capture microdissection coupled with microarray technology to identify nucleus-specific transcriptional networks.

Key words: ventromedial; hypothalamus; marker; VMH; expression; microarray; LCM; microdissection

\section{Introduction}

In vertebrates, several hypothalamic nuclei have been shown to play a pivotal role in controlling food intake and body weight (Hetherington and Ranson, 1940; Elmquist et al., 1999). Electrolytic, chemical, or genetic lesions of the ventromedial hypothalamic nucleus (VMH) result in obesity and hyperphagia, whereas lateral hypothalamic (LH) lesions result in weight loss and hypophagia (Owen et al., 1953; Marshall and Mayer, 1956; Bernardis et al., 1966; Majdic et al., 2002). These data formed the original basis for the dual-center hypothesis, which suggested that the LH functions as a feeding center, and the VMH functions as a satiety center. Subsets of VMH neurons are glucose sensitive, and this nucleus is a key mediator of the counter-regulatory response to hypoglycemia, which includes decreased insulin production and increased release of glucagon and catecholamines (Ono et al.,

Received Jan. 12, 2005; revised March 8, 2005; accepted March 9, 2005.

We thank Dr. Katia Manova and the staff of the Molecular Cytology Core Facility at the Sloan-Kettering Institute for valuable advice and assistance with laser-capture microdissection. We also thank the Albert Einstein College of Medicine Microarray Facility for printing the microarrays used in this study and Dr. Alison North at the Rockefeller University Bio-Imaging Resource Center for assistance with microscopy.

Correspondence should be addressed to Jeremy P. Segal, The Rockefeller University, 1230 York Avenue, Box 305, New York, NY 10021. E-mail: segalj@rockefeller.edu.

DOI:10.1523/JNEUROSCI.0158-05.2005

Copyright $\odot 2005$ Society for Neuroscience $\quad$ 0270-6474/05/254181-08\$15.00/0
1982; Borg et al., 1997, 1999). Additionally, the VMH expresses large amounts of the signaling form of the leptin receptor, implicating it in the response to this hormonal regulator of feeding and metabolism (Halaas et al., 1995; Mercer et al., 1996). In addition to its involvement in energy balance, the $\mathrm{VMH}$ is implicated in a wide array of processes, including, but not limited to, the lordosis response, thermogenesis, and salt and water balance (Wishart and Walls, 1975; Pfaff and Sakuma, 1979a,b; Fujimoto, 1980; Perkins et al., 1981). Although these neuroanatomic data establish the importance of the VMH, the cellular and molecular correlates of its functions are poorly understood. Thus, although several neuropeptides that mark defined neuronal types in the LH (melanin-concentrating hormone and orexin), arcuate nucleus (ARC) [proopiomelanocortin (POMC), neuropeptide Y (NPY), cocaine- and amphetamine-regulated transcript, and agoutirelated protein], and paraventricular nucleus (corticotropinreleasing hormone, growth hormone-releasing hormone, and oxytocin) have been identified, few markers for specific classes of VMH neurons are available (Elmquist et al., 1999).

In this report, we set out to identify a set of VMH-enriched genes that could be used as markers for the identification and functional analysis of specific cell types in this nucleus. Lasercapture microdissection (LCM) was used in conjunction with cDNA microarrays to isolate cDNAs enriched in the $\mathrm{VMH}$ rela- 
tive to the adjacent ARC and dorsomedial hypothalamus (DMH). LCM allows for far greater precision and reproducibility than the traditional punch-out approach, making it well suited for applications that require extremely accurate dissection of complex three-dimensional structures (Emmert-Buck et al., 1996; Bonaventure et al., 2002). Using this approach, we generated a set of nine validated VMH marker genes whose expression was confirmed by real-time PCR. As an additional confirmation, and to investigate possible subnuclear expression patterns, we also performed in situ hybridization histochemistry (ISHH) on three of these genes, cerebellin $1(C b \ln 1)$, pituitary adenylate $c y$ clase activating polypeptide (PACAP), and a novel expressed sequence tag (EST) that we further characterized. Finally, we show that the expression of one-half of the validated VMH marker genes is markedly diminished in the hypothalami of steroidogenic factor-1/Nr5a1 (SF-1) knock-out (KO) mice. These results further suggest that transcriptional profiling from specific nuclei can be used to uncover nucleus-specific transcriptional networks.

These VMH marker genes now provide an opportunity to analyze the specific functions of the different neuronal populations that compose this nucleus. With the advent of BAC transgenesis and other technologies, the availability of these marker genes enables a number of molecular genetic approaches including the specific labeling and characterization of the different cell types that constitute this important nucleus (Gong et al., 2003).

\section{Materials and Methods}

Sectioning and tissue staining for LCM. Eight-week-old female C57BL/6J mice were killed, and brains were dissected manually and frozen immediately in Tissue-Tek OCT 4583 compound (Sakura, Tokyo, Japan). The frozen blocks were sectioned on a cryostat (Leica, Nussloch, Germany) to a thickness of $10 \mu \mathrm{m}$. Sections were fixed for $1 \mathrm{~min}$ in $100 \% \mathrm{EtOH}$ and then rehydrated with a graded alcohol series $(95,75$, and $50 \%$; $30 \mathrm{~s}$ each) and stained for $1 \mathrm{~min}$ in filtered $0.5 \%$ cresyl violet acetate (Sigma, St. Louis, MO). Next, sections were again dehydrated with $\mathrm{EtOH}$ (50\% for $30 \mathrm{~s}, 75 \%$ for $30 \mathrm{~s}, 95 \%$ for $30 \mathrm{~s}$, and $100 \%$ for $1 \mathrm{~min}$ ) and finally were dehydrated with Histoclear (AGTC Bioproducts, Yorkshire, UK) for 1 min. All solutions were made with autoclaved $0.1 \%$ DEPC water.

Microdissection. The ARC, VMH, and DMH were microdissected out of a series of 10 evenly spaced Nissl-stained sections covering the region from 1.46 to $1.94 \mathrm{~mm}$ caudal to bregma, as defined by Paxinos and Franklin (2003) using a PixCell II laser-capture microdissection system (Arcturus Bioscience, Mountain View, CA). The collected tissue, adherent to the underside of the LCM cap, was then dissolved in digestion buffer (Stratagene, La Jolla, CA) and frozen at $-80^{\circ} \mathrm{C}$. Later, RNA was extracted from these samples using the Absolutely RNA microprep kit (Stratagene). Approximately 10 evenly spaced sections were pooled to eliminate any potential rostrocaudal gene expression bias. Typical pools contained $\sim 20$ ng of RNA.

Amplification and microarray hybridization. RNA was subjected to two rounds of T7-based linear amplification using MessageAmp (Ambion, Austin, TX), which produces large quantities of antisense RNA as product. Eight micrograms of each amplified sample were labeled with either cyanine 3 (Cy3) or Cy5 (Amersham Biosciences, Piscataway, NJ) dye using Superscript II (Invitrogen, Carlsbad, CA). Labeled probes were concentrated using YM-10 Microcon columns (Millipore, Bedford, MA) and hybridized onto cDNA arrays in a GeneTAC hybridization station (Genomic Solutions, Ann Arbor, MI). Two different cDNA arrays were probed. The first contained 27,588 features comprising Incyte (Wilmington, DE), National Cancer Institute, and IMAGE Consortium (Livermore, CA) clones with four bacterial genes as controls. The second array was made from a normalized mouse hypothalamic cDNA library comprising $\sim 5000$ clones, constructed by Dr. Marcelo Soares. This library was the result of the subtraction of a parent hypothalamic library with a mouse total brain library to select for hypothalamic-enriched clones. Both arrays were printed at the Albert Einstein College of Medicine Mi- croarray Facility. After washing, slides were imaged using a scanner (ScanArray Lite; GSI Lumonics, El Segundo, CA) and ScanArray Express software (PerkinElmer, Wellesley, MA). Results from each slide were normalized via an intensity-dependent normalization using a rankinvariant technique to select the normalization set (Tseng et al., 2001; Yang et al., 2002).

Real-time PCR. RNA from microdissected samples was reverse transcribed using TaqMan reverse-transcription reagents (Applied Biosystems, Foster City, CA), and real-time PCR was performed using TaqMan Universal PCR Master Mix (Applied Biosystems) with an ABI PRISM 7700 Sequence Detection system (Applied Biosystems) according to the recommendations of the manufacturer. Results were analyzed using SDS 1.9.1 software (PerkinElmer). Probe and primer sequences are all available by request.

In situ hybridization histochemistry. ISHH was performed as described previously (Marcus et al., 2001; Liu et al., 2003). Briefly, formaldehydefixed and sucrose-dehydrated $25 \mu \mathrm{m}$ frozen sections from 8-week-old female C57BL/6 mice (see Fig. 2) or 8-week-old SF-1 KO mice or littermate controls were mounted on Superfrost slides (Fisher Scientific, Houston, TX) and hybridized with either sense or antisense ${ }^{35} \mathrm{~S}$ probes for $C b \ln 1, P A C A P$, or $L B H 2$. Slides were washed and subsequently dipped in NTB2 photographic emulsion (Eastman Kodak, Rochester, NY) and left to expose for 4 weeks. The slides were then developed with D-19 developer (Eastman Kodak) and counterstained with thionin. Slides were then imaged on an Axioplan 2 imaging microscope (Zeiss, Oberkochen, Germany) fitted with a Plan Neofluar $5 \times / 0.15$ numerical aperture objective using a Spot Insight QE color digital camera. Mice with a brain-specific KO of SF-1 were generated using a conditional SF-1 allele and the nestin-Cre transgene (The Jackson Laboratory, Bar Harbor, ME), and sections from the mediobasal hypothalamus were analyzed by in situ hybridization with the Cbln1 probe.

Fluorescence-activated cell sorting of SF-1 neurons. Mice bearing an enhanced green fluorescent protein (eGFP) transgene under the control of the SF-1 promoter (SF-1-eGFP) have been described previously (Stallings et al., 2002). These mice were bred onto wild-type (WT), SF$1^{+/-}$(heterozygote), or SF-1 ${ }^{-1-}$ (KO) backgrounds, and males were killed at embryonic day 16.5. Brains were dissected and trypsinized, and eGFP-positive neurons were resolved by fluorescence-activated cell sorting (FACS) essentially as described previously (Motoike et al., 2000). RNA was isolated using Trizol (Invitrogen) and reverse transcribed using SuperScript III reverse transcriptase (Invitrogen). Real-time PCR was performed as described above.

\section{Results}

LCM was used to isolate tissue from the VMH, ARC, and DMH of 8-week-old female C57BL/6J mice. The dissected tissue and the residual sections from a typical microdissection are shown (Fig. 1). We focused on the dorsomedial VMH for two reasons. First, this area contains nearly all of the leptin receptor in this nucleus, implicating this area in the response to leptin and in energy homeostasis (Mercer et al., 1996). Second, it is also the most neuron-dense region of the VMH. Dissecting only this subset of the VMH minimized glial contamination, which was found in some cases to dilute the contributions from VMH neurons. As sources of RNA for comparison with the VMH, the ARC was chosen because several ARC-specific genes have already been identified and because this region is adjacent to the $\mathrm{VMH}$ (Elmquist, 2001). We also analyzed the DMH, another mediobasal nucleus adjacent to the VMH with similar neuron density also implicated in energy balance and other physiologic processes. RNA samples from $\sim 10$ evenly spaced sections from each nucleus were pooled to minimize anterior-posterior bias and amplified using a T7-based linear system (MessageAmp; Ambion). The antisense RNA products from each nucleus were labeled with either Cy3 or Cy5 dye (Amersham Biosciences) and used to probe each of two different cDNA microarrays. The first array was a collection of $\sim 28,000$ cDNA clones comprising $\sim 20,000$ unique 


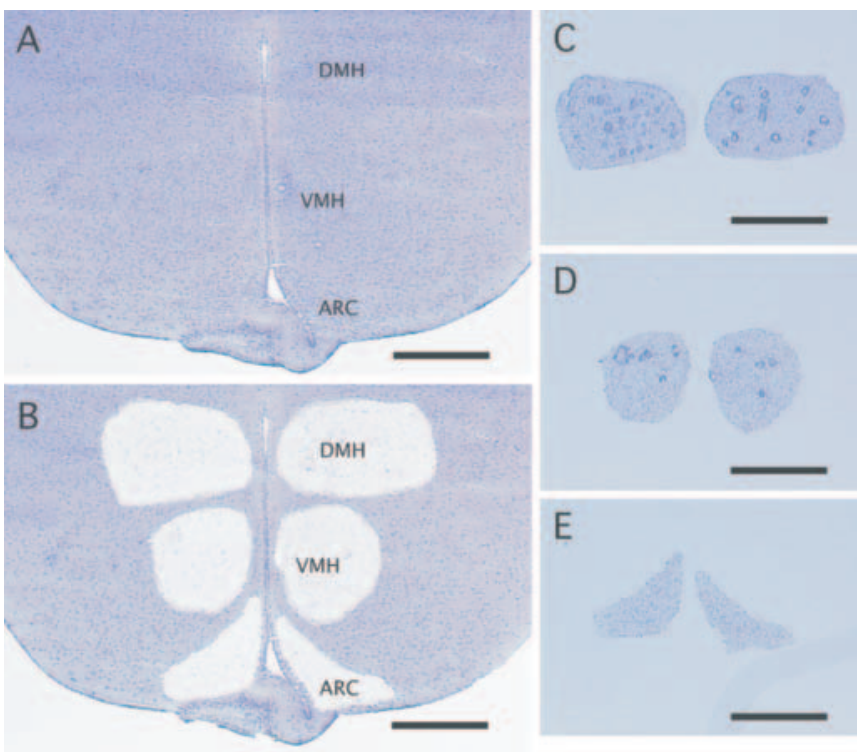

Figure 1. Laser-capture microdissection of hypothalamic nuclei. $A, B, A$ Nissl-stained section of mouse hypothalamus before $(\boldsymbol{A})$ and after $(\boldsymbol{B})$ sequential dissection of VMH, DMH, and ARC tissue. $\boldsymbol{C}-\boldsymbol{E}$, Images of dissected DMH ( $\boldsymbol{C}$, VMH (D), and ARC $(\boldsymbol{E})$ tissue, which is adherent to the cap. Scale bars, $500 \mu \mathrm{m}$.

genes. The second array was composed of a set of $\sim 5000 \mathrm{cDNA}$ clones from a normalized mouse hypothalamic cDNA library, which was selected for hypothalamic enrichment by subtraction against a library from total brain.

The labeled RNA from each of the three nuclei was compared in pairwise manner against labeled RNA from each of the other two, using reverse-color hybridization as an added control (Fig. $2 A-C)$. Overall, it was evident that the vast majority of genes $(>99 \%)$ are expressed at similar levels among the three nuclei. Nonetheless, it was possible to identify individual gene products that were enriched in specific nuclei. These genes were analyzed further with respect to their relative levels of expression in the three nuclei that were dissected.

In the arcuate nucleus, a number of previously identified ARC-specific genes were revealed, including POMC, NPY, and neurokinin B (Gee et al., 1983; Gehlert et al., 1987; Marksteiner et al., 1992). We also noted substantial overlap between the set of genes with high ARC/DMH ratios and those with high ARC/ VMH ratios (Fig. 2D). This was expected because many ARCenriched genes have already been identified. This same pattern was evident when analyzing the expression profile of the VMHenriched genes insofar as genes with high VMH/ARC ratios were also enriched in the VMH versus the DMH (i.e., they had high VMH/DMH ratios) (Fig. $2 E$ ). In contrast, there was very little overlap between genes with high DMH/ARC ratios and those with high $\mathrm{DMH} / \mathrm{VMH}$ ratios (Fig. $2 \mathrm{~F}$ ). Together, this suggests that the ARC and VMH express a number of nucleus-enriched genes relative to adjacent areas of the mediobasal hypothalamus. In contrast, it was substantially more difficult to identify RNAs in $\mathrm{DMH}$ that were not expressed in either the VMH or ARC.

The genes with increased signals in the VMH samples compared with both the DMH and ARC were further analyzed to confirm that they were in fact VMH-enriched marker genes. In these experiments, we were especially interested in genes that showed the highest geometric mean of VMH/ARC and VMH/ $\mathrm{DMH}$ ratios (i.e., a VMH score). Table 1 lists the genes with a $\mathrm{VMH}$ score $>4.0$. The list, which is headed by the canonical
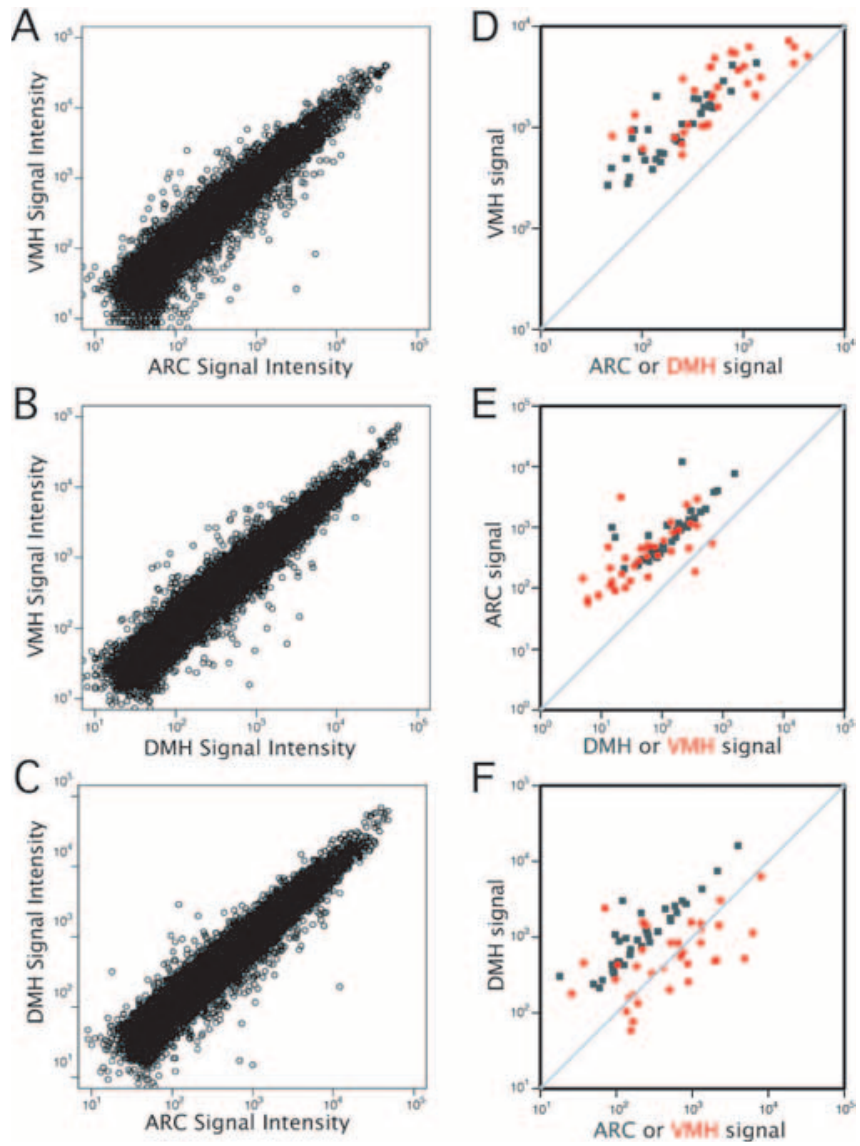

Figure 2. Microarray analysis of RNA from hypothalamic nuclei. Normalized ARC versus VMH $(\boldsymbol{A})$, DMH versus VMH (B), and ARC versus DMH (C) CDNA microarray results on log-log plots. D$\boldsymbol{F}$, Marker gene comparisons using similar intensity-value plots. $\boldsymbol{D}$, Genes with highest VMH/ ARC ratios (gray squares) also display high VMH/DMH ratios (red circles). $\boldsymbol{E}$, Genes with highest ARC/DMH ratios (gray squares) also display high ARC/VMH ratios (red circles). $\boldsymbol{F}$, In contrast, only a small number of genes with high DMH/ARC ratios (gray squares) display high DMH/VMH ratios (red circles).

VMH marker gene SF-1, includes neuropeptides, ESTs, and several other genes. To validate these microarray data, real-time PCR was performed for each of the top $12 \mathrm{VMH}$ candidate genes on independent samples of RNA collected from the ARC, VMH, and DMH using LCM (Fig. 3A). These data confirmed the microarray results for 9 of these 12 genes: SF-1, PACAP, Cbln1, EST XM_354697, Slit3, guanine deaminase, TenM2, 3-O-sulfotransferase 4 (3-OST-4), and EST AA982708. Although the realtime PCR data were consistent with the original microarray results for these nine genes, thus validating the screening approach, the data for cytochrome P450 CYP2J9, D123, and ARP-1 did not recapitulate the array results. The basis for the apparent discrepancy for these three genes may be a result of cross-hybridization of RNAs with CDNA probes for other genes with sequence similarity. In addition, three of these nine genes were present exclusively on the 5000 gene hypothalamus-enriched array, highlighting the utility of using enriched libraries and suggesting that some $\mathrm{VMH}$ genes are not expressed or are expressed at low levels elsewhere in brain.

For the reasons stated above, the original dissection focused on the dorsomedial $\mathrm{VMH}$, raising the possibility that these cDNAs might be localized in this region of the VMH. To further ensure that this screening system indeed produced legitimate $\mathrm{VMH}$ markers and to establish their distribution within the 
$\mathrm{VMH}$, ISHH was performed for three of the genes: PACAP, Cbln1, and the hypothalamic array EST XM_354697 (Fig. 3B$D)$. Cbln1, initially isolated from rat cerebellum as a 16 aa peptide, is known to be expressed in Purkinje cells of the cerebellum and cartwheel cells in the dorsal cochlear nucleus, but histochemical analyses of the hypothalamus have not been reported (Slemmon et al., 1984; Mugnaini and Morgan, 1987). PACAP is a neuropeptide shown previously to be highly expressed in the VMH (Hannibal, 2002). The EST from the hypothalamic library is listed in GenBank under the accession number XM_354697 and the name "similar to limb-bud and heart.” Its characteristics are described in greater detail below.

ISHH confirmed that, within the hypothalamus, these three genes are highly enriched in the $\mathrm{VMH}$, with very low expression in other areas of the hypothalamus, including the ARC and DMH. All three genes show a similar anatomical distribution within the $\mathrm{VMH}$, with some expression in all regions but a gradient of expression from the dorsomedial (most prominent) to the central (intermediate) to the ventrolateral (least prominent).

The VMH-enriched EST XM_354697 has not been characterized previously. This gene was present in multiple copies on the hypothalamus-enriched array, but was not a constituent of the 28,000 gene library. Northern blotting showed that the $\sim 800 \mathrm{bp}$ transcript for this gene is abundantly expressed in the hypothalamus, with expression at lower levels in other brain regions, as well as in the spleen (Fig. 4). The predicted product of this transcript is a 114 aa protein, which shares a 29 aa stretch of $86 \%$ identity with limb bud and heart ( $\mathrm{LBH})$, a putative transcription factor thought to play a role in limb and heart development (Briegel and Joyner, 2001). Thus, based on the guidelines of the International Committee on Standardized Genetic Nomenclature for Mice, we propose to name this gene $\mathrm{LBH} 2$. A comparison of the protein sequences of $\mathrm{LBH} 2$ with $\mathrm{LBH}$ and the homologous proteins "rat similar to XLCL2 protein" and "EST human LOC350101 protein" shows that this gene is evolutionarily conserved, especially within a middle stretch of 50 aa (supplemental data, available at www.jneurosci.org as supplemental material). An LBH2-eGFP fusion protein expressed in 293T cells under the control of the cytomegalovirus promoter showed cytoplasmic expression of the protein product (data not shown).

The identification of the SF-1 gene in this screen suggested that this transcription factor might regulate some of the other VMH-enriched markers. SF-1 is a transcription factor first identified based on its ability to bind to a common upstream region shared by a group of cytochrome $\mathrm{P} 450$ steroid hydroxylases in the adrenal cortex (Lala et al., 1992). SF-1 was subsequently found to play an important role in the development of the $\mathrm{VMH}$, because SF-1 knock-out mice display "agenesis" of the VMH attributable to abnormal migration of VMH neurons (Lala et al., 1992; Davis et al., 2004). The formation of the VMH during development relies on coordinated migration of neurons into their correct position (Davis et al., 2004). In SF-1 knock-out mice, there is a diffuse, disorganized collection of poorly developed VMH neurons outside their normal anatomic position. As a result of the abnormal development of this nucleus, these mice develop lateonset obesity despite normal food intake (Majdic et al., 2002).

Thus, as a first effort to define a genetic network that might mediate VMH-enriched expression, we analyzed the expression of the confirmed VMH-enriched transcripts in SF-1 knock-out mice. Genes that are dysregulated in SF-1 neurons would represent potential SF-1 target genes that might play a role in the proper development of this nucleus. Using a previously described SF-1-eGFP transgenic line, we FACS sorted SF-1 neurons from WT and SF-1 knock-out and SF-1 heterozygous mice (Stallings et al., 2002). Real-time PCR for each of the bona fide VMH marker genes (excluding SF-1) was then performed on RNA from these sorted neurons. The RNA levels for four of the eight genes ( Cbln1, Slit3, TenM2, and EST AA982708) were found to be markedly reduced in samples from SF-1 ${ }^{-1-}$ mutant neurons versus wildtype or heterozygote neurons. (Fig. 5A). In contrast, PACAP and guanine deaminase were induced in the GFP-labeled neurons from the mutant animals, perhaps revealing a lack of feedback signaling.

To confirm this result, we performed ISHH for $C b \ln 1$ on brain sections from wild-type and brain-specific SF-1 knock-out mice (Fig. 5B-C). In sections from $\mathrm{KO}$ mice, the SF-1 neurons expressed significantly less Cbln1 mRNA compared with sections from wild-type animals. The signal intensity for Cbln 1 was unaffected in the neighboring zona incerta.

\section{Discussion}

The use of marker genes to dissect complex neural circuits has been applied previously in studies of several brain regions, revealing important and, in some cases, divergent responses of specific neurons in specific brain regions (Elias et al., 1999; Pinto et al., 2004). Although several lines of evidence have established that the VMH plays an important role in controlling food intake, glucose metabolism, and body weight (Elmquist et al., 1999), efforts to determine how specific classes of VMH neurons mediate these processes have been hampered by the lack of a set of marker genes that could facilitate a molecular analysis of their function. The importance of understanding the functional roles of specific neurons in this nucleus is further amplified by the observation that VMH-specific knock-out of the leptin receptor leads to increased adiposity and body weight (H. Dhillon, personal communication). In these studies, it was not known which $\mathrm{VMH}$ neurons are responsible for this effect.

In this report, we used LCM coupled with cDNA microarrays to generate an initial set of VMH-enriched genes. This set can be expanded using a similar approach in combination with microarrays composed of different clones from those used in this report. A total of nine transcripts were isolated that were highly enriched 

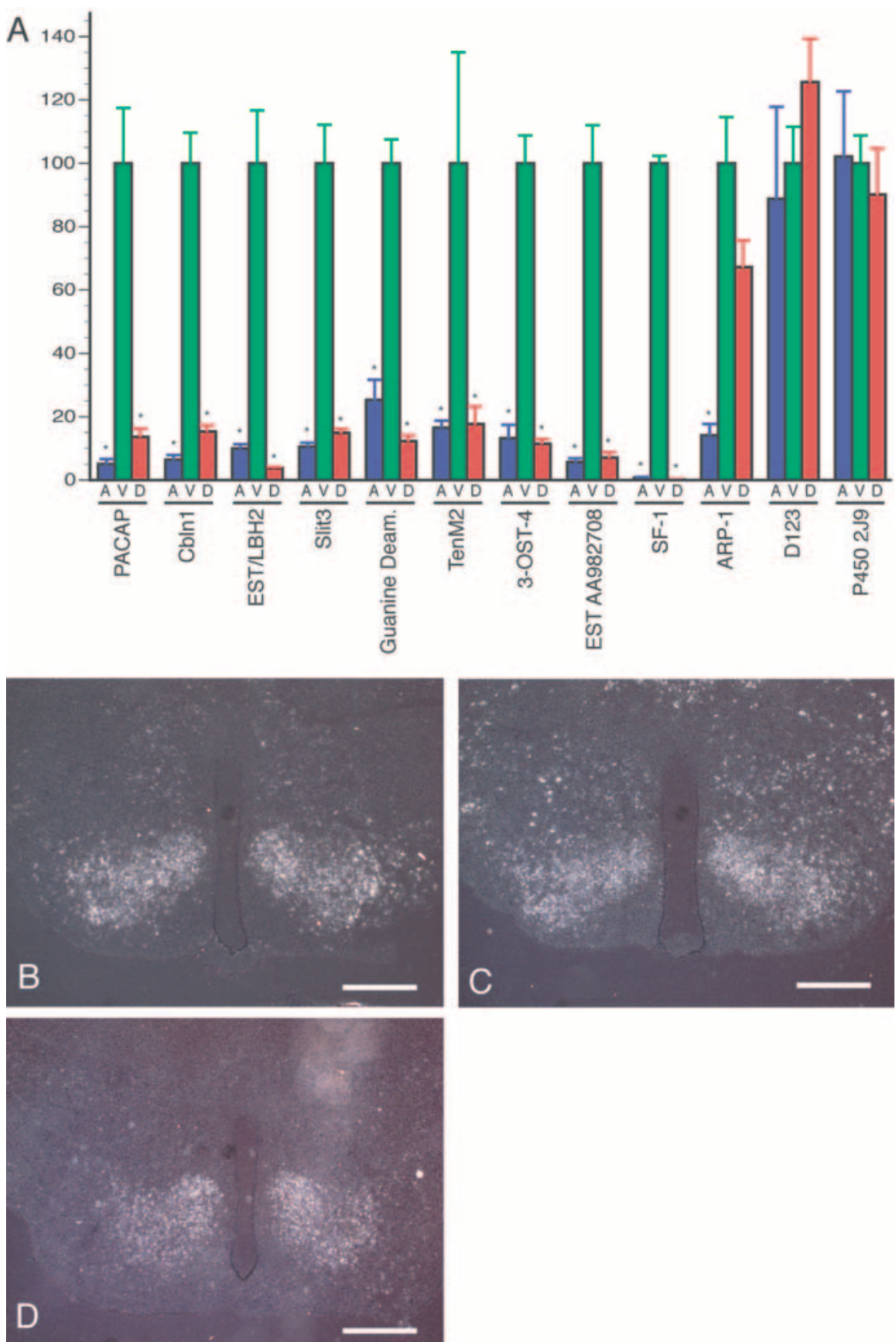

Figure 3. Confirmation of microarray results by real-time PCR and ISHH. $A$, Twelve VMH candidate markers (PACAP, Cbln1, EST/LBH2, Slit3, guanine deaminase, TenM2, 3-OST-4, EST 982708, SF-1, ARP-1, D123, and cytochrome P450 (YP2J9) tested by real-time PCR analysis using RNA from microdissected ARC (A), VMH (V), and DMH (D) tissue. For each gene, expression was normalized to cyclophilin, and results from different nuclei were then normalized to the VMH, with VMH expression set at $100 \%$. Values are expressed as mean \pm SEM. Statistical significance, ${ }^{*} p<0.05$. $\boldsymbol{B}-\boldsymbol{D}$, Dark-field images $(5 \times)$ of 8 -week-old female mouse hypothalamus hybridized with antisense probes for PACAP (B), Cbln1 (C), and EST XM_354697/LBH2 (D). Scale bars, 500 $\mu \mathrm{m}$. Error bars represent SEM.

in the $\mathrm{VMH}$ relative to the DMH and ARC. These markers can now be used to define subpopulations of $\mathrm{VMH}$ neurons as a prelude to studies of the function and circuitry of the individual subsets. It is noteworthy that the expression levels of most genes on the arrays were quite similar among the three nuclei analyzed and that the DMH expressed very few genes with high ratios versus both the ARC and VMH.

ISHH for three of the nine VMH-enriched genes $(C b \ln 1$, $P A C A P$, and a novel gene we named $L B H 2$ ) was used to refine the subnuclear distribution of these genes as well as to further validate the results of the real-time PCR. These genes were chosen based on their robust VMH expression as well as their potential functional role(s). $P A C A P$ encodes a neuropeptide that has been strongly implicated previously in metabolic function. PACAP peptide, when administered to mice via the third ventricle, leads to a sharp reduction of food intake (Mizuno et al., 1998). Additionally, PACAP knock-out mice exhibit severe metabolic disorders, including impairments to thermogenesis and the counterregulatory response to hypoglycemia (Gray et al., 2001, 2002). The VMH has been shown to play a role in both of these processes, suggesting that PACAP may contribute to some portion of these $\mathrm{VMH}$ functions (Perkins et al., 1981; Borg et al., 1997). Cerebellin 1 was originally identified as a 16 aa peptide, isolated from rat cerebellum (Slemmon et al., 1984). The precursor protein from which this 16 aa peptide is derived displays some similarity to circulating complement $\mathrm{C1q}$, suggesting that this precursor protein may be the authentic ligand for cerebellin signaling (Urade et al., 1991). Although Cbln1 has been shown by radioimmunoassay to be expressed in the hypothalamus, its distribution within this region has not been examined (Satoh et al., 1997). Here, we show that the main site of $C b \ln 1$ expression in the hypothalamus is indeed the $\mathrm{VMH}$. $\mathrm{LBH} 2$ is a novel gene that shares significant homology with $L B H$, a presumed transcription factor postulated to play a role in limb and heart development (Briegel and Joyner, 2001). Sequence alignment shows this new gene to be evolutionarily conserved among a number of species. The mRNA for this gene is short ( $\sim 800 \mathrm{bp})$, and the vast majority of its expression in the body is confined to the VMH. The function of this $\mathrm{VMH}$-enriched transcript awaits additional studies, currently underway.

The ISHH results were similar for each of these three genes with expression in all anatomic subdivisions of the $\mathrm{VMH}$ but with the strongest expression in the dorsomedial $\mathrm{VMH}$, in which neurons are most densely packed. Within the hypothalamus, the VMH-enrichment of the tested RNAs, as assessed using ISHH, validates the approach and suggests that the other genes enriched in the VMH using microarray analysis followed by realtime PCR might also merit additional study. These genes include Slit3, 3-OST-4, TenM2, guanine deaminase, and EST AA982708. Among these genes, 3-OST-4 belongs to a family of sulfotransferases that chemically modify heparan sulfate proteoglycans (HSPGs) (Shworak et al., 1999). These are large cell-surface complexes that bind extracellular ligands and are believed to play a 


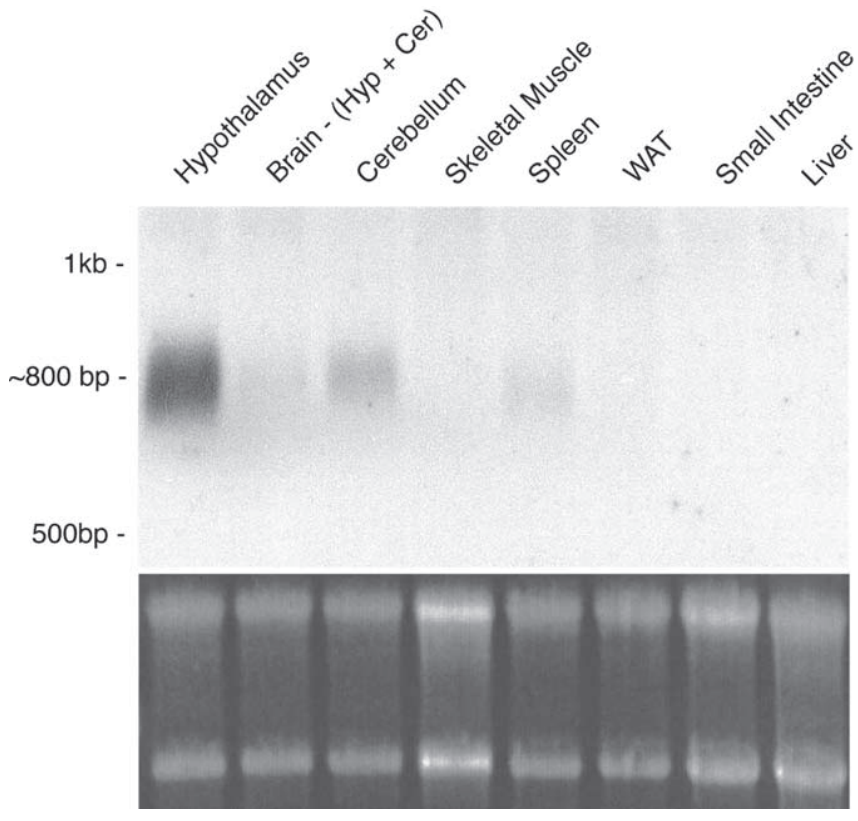

Figure 4. The novel gene LBH2. Tissue panel Northern blot for EST XM_354697/LBH2. Ethidium bromide staining of $28 \mathrm{~S}$ and $18 \mathrm{~S}$ ribosomal bands is shown as a loading control. Cer, Cerebellum; Hyp, hypothalamus; WAT, white adipose tissue.
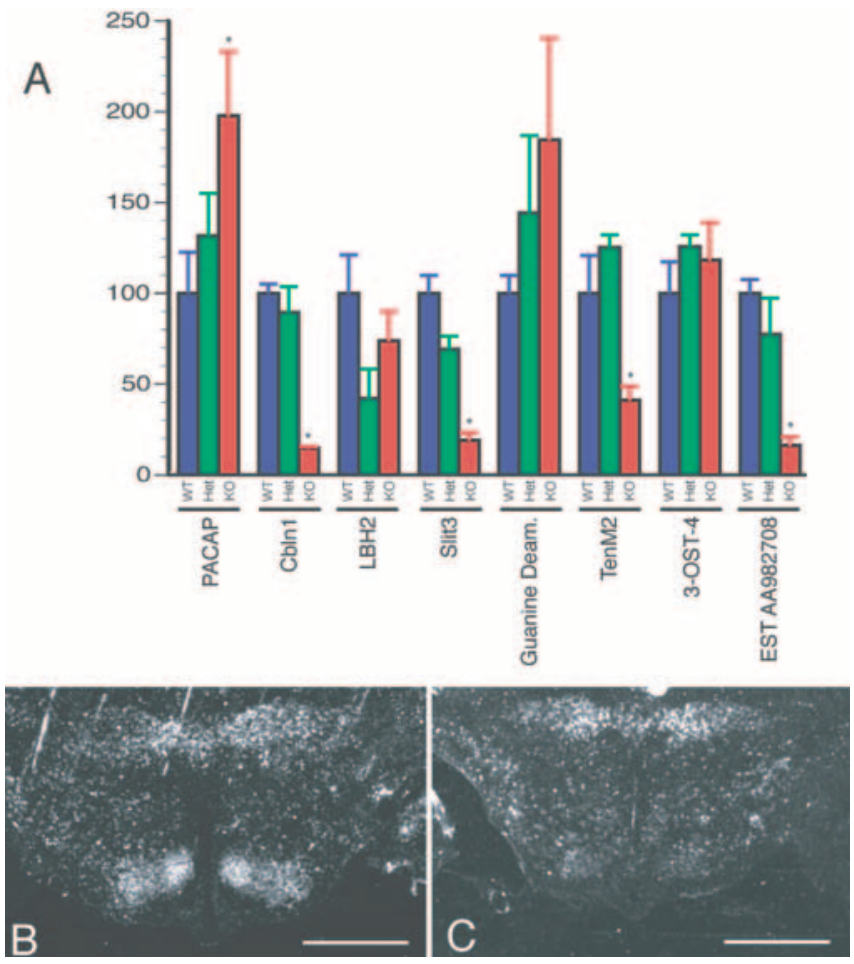

Figure 5. Expression of marker genes in SF-1 KO mice. $\boldsymbol{A}$, Real-time PCR results for VMH marker genes on RNA from FACS-sorted SF-1- eGFP neurons on WT, SF-1 heterozygote (Het), and SF-1 KO background (KO). All data points are normalized to cyclophilin, with WT values set at $100 \%$. Dark-field images of hybridizations with Cbln1 antisense probe on brain sections from WT control mice $(\boldsymbol{A})$ and brain-specific SF-1 KO mice $(\boldsymbol{B})$. Scale bars, $1 \mathrm{~mm}$. Error bars represent SEM.

role in, among other things, the modulation of intercellular signaling (Bernfield et al., 1999). Transgenic mice expressing another HSPG, syndecan-1, in multiple tissues including the hypothalamus, display obesity secondary to impairment of $\alpha$-melanocyte-stimulating hormone signaling in the hypothala- mus (Reizes et al., 2001, 2003). HSPGs and their modifying enzymes are often tightly regulated to respond to stimuli, suggesting that 3-OST-4 may play a role in signal modification in the VMH. Little is known about EST AA982708 (located on mouse chromosome 2), but the fact that the level of its RNA is reduced in hypothalamus from SF-1 knock-out mice suggests that it too may merit additional study. Like $\mathrm{LBH} 2$, this transcript was present only on the subtracted hypothalamic cDNA array and not on the 28,000 gene array, which was largely composed of embryonic and adult mouse cDNA clones. Thus, it appears that, as was the case for $\mathrm{LBH} 2$, the hypothalamus (and by extension the $\mathrm{VMH}$ ) is the primary site of expression of this EST in the mouse.

Several of the VMH-enriched genes were dysregulated in SF-1 knock-out mice. SF-1 is an orphan nuclear receptor that plays a critical role in the embryonic development of the VMH (Ikeda et al., 1995). Proper differentiation and migration of VMH neurons during development is presumed to be associated with the activation of a number of SF-1 target genes. Although direct targets of SF-1 have been identified in the adrenal gland, including cholesterol side-chain cleavage enzyme, steroid 21-hydroxylase and the aldosterone synthase isozyme of steroid $11 \beta$-hydroxylase, few of its VMH targets have been identified (Parker and Schimmer, 1997). Four of eight VMH markers tested (Cbln1, Slit3, TenM2, and EST AA982708) were significantly downregulated in mutant neurons. Among these genes, Slit3 especially stands out, because the Slit genes, along with their Robo receptors, are known regulators of cell migration and axon guidance (Wu et al., 1999). It is likely that some or all of these genes are direct or indirect targets of SF-1 and may play a role in the development and/or migration of $\mathrm{VMH}$ neurons.

The marker genes reported here thus constitute a set of reagents that can be used to establish the number of distinct cell types in the VMH as a prelude to future efforts to study their function. The definition of neuronal subtypes based on the expression of marker gene expression rather than anatomic localization or morphology offers a number of experimental advantages. For example, it has been shown that the POMC and NPY neurons in the ARC, which are not distinguishable on the basis of localization or morphology, display opposing responses to treatment with leptin, with regard to both activity and plasticity (Elias et al., 1999; Pinto et al., 2004). Defining neuronal subpopulations on the basis of gene expression is additionally advantageous, because it allows for the introduction of a marker or other genes specifically to those neurons using BAC-mediated transgenesis. BACs can be easily modified to express a transgene usually under the control of the full set of regulatory elements necessary for the eutopic expression of that gene (Gong et al., 2002). BAC transgenic mice expressing GFP in specific classes of VMH neurons would be a powerful tool for electrophysiological studies, electron microscopy-based assays of neuronal plasticity and synaptogenesis, cell culture assays, and gene expression studies of nuclear subpopulations (Pinto et al., 2004; Roseberry et al., 2004). Additionally, mice expressing Cre recombinase in those same subsets would be useful for targeted knock-outs and neuronal tracing studies using conditional pseudorabies virus strains or other neuronal tracers (DeFalco et al., 2001).

The coupling of LCM with microarray analysis thus represents a powerful systematic approach to probe these areas, because it offers a means by which to generate genetic markers based directly on cytoarchitectural features. However, although it was straightforward to identify genes enriched in the VMH and $\mathrm{ARC}$, it was more difficult to identify DMH-specific genes. It is not clear whether there is a paucity of marker genes in this nu- 
cleus. Alternatively, there may exist DMH-enriched genes that were not represented on the two arrays that were used, although the overall number of genes probed and the use of the hypothalamic-enriched library mitigate this possibility.

For the VMH, the marker genes that were isolated may prove valuable as a basis for defining neuronal subpopulations and also represent powerful tools with which to investigate the function of those very subsets. When combined with knock-out mice, in this case SF-1, this approach can also be used to begin to identify putative elements of networks of genes that play a role in the development and/or function of specific brain regions. A similar approach can be easily used in analogous studies of other brain regions.

\section{References}

Bernardis LL, Bahorsky M, Bohacek L (1966) Development of hyperphagia in female rats with ventromedial hypothalamic lesions placed at four different ages. Experientia 22:593-595.

Bernfield M, Gotte M, Park PW, Reizes O, Fitzgerald ML, Lincecum J, Zako M (1999) Functions of cell surface heparan sulfate proteoglycans. Annu Rev Biochem 68:729-777.

Bonaventure P, Guo H, Tian B, Liu X, Bittner A, Roland B, Salunga R, Ma XJ, Kamme F, Meurers B, Bakker M, Jurzak M, Leysen JE, Erlander MG (2002) Nuclei and subnuclei gene expression profiling in mammalian brain. Brain Res 943:38-47.

Borg MA, Sherwin RS, Borg WP, Tamborlane WV, Shulman GI (1997) Local ventromedial hypothalamus glucose perfusion blocks counterregulation during systemic hypoglycemia in awake rats. J Clin Invest 99:361-365.

Borg MA, Borg WP, Tamborlane WV, Brines ML, Shulman GI, Sherwin RS (1999) Chronic hypoglycemia and diabetes impair counterregulation induced by localized 2-deoxy-glucose perfusion of the ventromedial hypothalamus in rats. Diabetes 48:584-587.

Briegel KJ, Joyner AL (2001) Identification and characterization of Lbh, a novel conserved nuclear protein expressed during early limb and heart development. Dev Biol 233:291-304.

Davis AM, Seney ML, Stallings NR, Zhao L, Parker KL, Tobet SA (2004) Loss of steroidogenic factor 1 alters cellular topography in the mouse ventromedial nucleus of the hypothalamus. J Neurobiol 60:424-436.

DeFalco J, Tomishima M, Liu H, Zhao C, Cai X, Marth JD, Enquist L, Friedman JM (2001) Virus-assisted mapping of neural inputs to a feeding center in the hypothalamus. Science 291:2608-2613.

Elias CF, Aschkenasi C, Lee C, Kelly J, Ahima RS, Bjorbaek C, Flier JS, Saper CB, Elmquist JK (1999) Leptin differentially regulates NPY and POMC neurons projecting to the lateral hypothalamic area. Neuron 23:775-786.

Elmquist JK (2001) Hypothalamic pathways underlying the endocrine, autonomic, and behavioral effects of leptin. Int J Obes Relat Metab Disord 25 [Suppl 5]:S78-S82.

Elmquist JK, Elias CF, Saper CB (1999) From lesions to leptin: hypothalamic control of food intake and body weight. Neuron 22:221-232.

Emmert-Buck MR, Bonner RF, Smith PD, Chuaqui RF, Zhuang Z, Goldstein SR, Weiss RA, Liotta LA (1996) Laser capture microdissection. Science 274:998-1001.

Fujimoto S (1980) The effect of prostaglandin E2 microinjected into the rat hypothalamus on urinary excretion of water and sodium. Br J Pharmacol 70:415-417.

Gee CE, Chen CL, Roberts JL, Thompson R, Watson SJ (1983) Identification of proopiomelanocortin neurones in rat hypothalamus by in situ cDNA-mRNA hybridization. Nature 306:374-376.

Gehlert DR, Chronwall BM, Schafer MP, O’Donohue TL (1987) Localization of neuropeptide $Y$ messenger ribonucleic acid in rat and mouse brain by in situ hybridization. Synapse 1:25-31.

Gong S, Yang XW, Li C, Heintz N (2002) Highly efficient modification of bacterial artificial chromosomes (BACs) using novel shuttle vectors containing the R6Kgamma origin of replication. Genome Res 12:1992-1998.

Gong S, Zheng C, Doughty ML, Losos K, Didkovsky N, Schambra UB, Nowak NJ, Joyner A, Leblanc G, Hatten ME, Heintz N (2003) A gene expression atlas of the central nervous system based on bacterial artificial chromosomes. Nature 425:917-925.

Gray SL, Cummings KJ, Jirik FR, Sherwood NM (2001) Targeted disruption of the pituitary adenylate cyclase-activating polypeptide gene results in early postnatal death associated with dysfunction of lipid and carbohydrate metabolism. Mol Endocrinol 15:1739-1747.

Gray SL, Yamaguchi N, Vencova P, Sherwood NM (2002) Temperaturesensitive phenotype in mice lacking pituitary adenylate cyclase-activating polypeptide. Endocrinology 143:3946-3954.

Halaas JL, Gajiwala KS, Maffei M, Cohen SL, Chait BT, Rabinowitz D, Lallone RL, Burley SK, Friedman JM (1995) Weight-reducing effects of the plasma protein encoded by the obese gene. Science 269:543-546.

Hannibal J (2002) Pituitary adenylate cyclase-activating peptide in the rat central nervous system: an immunohistochemical and in situ hybridization study. J Comp Neurol 453:389-417.

Hetherington AW, Ranson SW (1940) Hypothalamic lesions and adiposity in the rat. Anat Rec 78:149-172.

Ikeda Y, Luo X, Abbud R, Nilson JH, Parker KL (1995) The nuclear receptor steroidogenic factor 1 is essential for the formation of the ventromedial hypothalamic nucleus. Mol Endocrinol 9:478-486.

Lala DS, Rice DA, Parker KL (1992) Steroidogenic factor I, a key regulator of steroidogenic enzyme expression, is the mouse homolog of fushi tarazufactor I. Mol Endocrinol 6:1249-1258.

Liu H, Kishi T, Roseberry AG, Cai X, Lee CE, Montez JM, Friedman JM, Elmquist JK (2003) Transgenic mice expressing green fluorescent protein under the control of the melanocortin-4 receptor promoter. J Neurosci 23:7143-7154.

Majdic G, Young M, Gomez-Sanchez E, Anderson P, Szczepaniak LS, Dobbins RL, McGarry JD, Parker KL (2002) Knockout mice lacking steroidogenic factor 1 are a novel genetic model of hypothalamic obesity. Endocrinology 143:607-614.

Marcus JN, Aschkenasi CJ, Lee CE, Chemelli RM, Saper CB, Yanagisawa M, Elmquist JK (2001) Differential expression of orexin receptors 1 and 2 in the rat brain. J Comp Neurol 435:6-25.

Marksteiner J, Sperk G, Krause JE (1992) Distribution of neurons expressing neurokinin B in the rat brain: immunohistochemistry and in situ hybridization. J Comp Neurol 317:341-356.

Marshall NB, Mayer J (1956) Specificity of gold thioglucose for ventromedial hypothalamic lesions and hyperphagia. Nature 178:1399-1400.

Mercer JG, Hoggard N, Williams LM, Lawrence CB, Hannah LT, Trayhurn P (1996) Localization of leptin receptor mRNA and the long form splice variant $(\mathrm{Ob}-\mathrm{Rb})$ in mouse hypothalamus and adjacent brain regions by in situ hybridization. FEBS Lett 387:113-116.

Mizuno Y, Kondo K, Terashima Y, Arima H, Murase T, Oiso Y (1998) Anorectic effect of pituitary adenylate cyclase activating polypeptide (PACAP) in rats: lack of evidence for involvement of hypothalamic neuropeptide gene expression. J Neuroendocrinol 10:611-616.

Motoike T, Loughna S, Perens E, Roman BL, Liao W, Chau TC, Richardson CD, Kawate T, Kuno J, Weinstein BM, Stainier DY, Sato TN (2000) Universal GFP reporter for the study of vascular development. Genesis 28:75-81.

Mugnaini E, Morgan JI (1987) The neuropeptide cerebellin is a marker for two similar neuronal circuits in rat brain. Proc Natl Acad Sci USA 84:8692-8696.

Ono T, Nishino H, Fukuda M, Sasaki K, Muramoto K, Oomura Y (1982) Glucoresponsive neurons in rat ventromedial hypothalamic tissue slices in vitro. Brain Res 232:494-499.

Owen JAJ, Parson W, Crispell KR (1953) Dietary dilution studies in gold thioglucose induced obesity in the mouse. Metabolism 2:362-366.

Parker KL, Schimmer BP (1997) Steroidogenic factor 1: a key determinant of endocrine development and function. Endocr Rev 18:361-377.

Paxinos G, Franklin KBJ (2003) The mouse brain in stereotaxic coordinates: compact second edition. San Diego: Academic.

Perkins MN, Rothwell NJ, Stock MJ, Stone TW (1981) Activation of brown adipose tissue thermogenesis by the ventromedial hypothalamus. Nature 289:401-402.

Pfaff DW, Sakuma Y (1979a) Facilitation of the lordosis reflex of female rats from the ventromedial nucleus of the hypothalamus. J Physiol (Lond) 288:189-202.

Pfaff DW, Sakuma Y (1979b) Deficit in the lordosis reflex of female rats caused by lesions in the ventromedial nucleus of the hypothalamus. J Physiol (Lond) 288:203-210.

Pinto S, Roseberry AG, Liu H, Diano S, Shanabrough M, Cai X, Friedman JM, Horvath TL (2004) Rapid rewiring of arcuate nucleus feeding circuits by leptin. Science 304:110-115. 
Reizes O, Lincecum J, Wang Z, Goldberger O, Huang L, Kaksonen M, Ahima R, Hinkes MT, Barsh GS, Rauvala H, Bernfield M (2001) Transgenic expression of syndecan-1 uncovers a physiological control of feeding behavior by syndecan-3. Cell 106:105-116.

Reizes O, Benoit SC, Strader AD, Clegg DJ, Akunuru S, Seeley RJ (2003) Syndecan-3 modulates food intake by interacting with the melanocortin/ AgRP pathway. Ann NY Acad Sci 994:66-73.

Roseberry AG, Liu H, Jackson AC, Cai X, Friedman JM (2004) Neuropeptide Y-mediated inhibition of proopiomelanocortin neurons in the arcuate nucleus shows enhanced desensitization in ob/ob mice. Neuron 41:711-722.

Satoh F, Takahashi K, Murakami O, Totsune K, Ohneda M, Mizuno Y, Sone M, Miura Y, Takase S, Hayashi Y, Sasano H, Mouri T (1997) Cerebellin and cerebellin mRNA in the human brain, adrenal glands and the tumour tissues of adrenal tumour, ganglioneuroblastoma and neuroblastoma. J Endocrinol 154:27-34.

Shworak NW, Liu J, Petros LM, Zhang L, Kobayashi M, Copeland NG, Jenkins NA, Rosenberg RD (1999) Multiple isoforms of heparan sulfate D-glucosaminyl 3-O-sulfotransferase. Isolation, characterization, and expression of human cDNAs and identification of distinct genomic loci. J Biol Chem 274:5170-5184.

Slemmon J, Blacher R, Danho W, Hempstead J, Morgan JI (1984) Isolation and sequencing of two cerebellum-specific peptides. Proc Natl Acad Sci USA 81:6866-6870.

Stallings NR, Hanley NA, Majdic G, Zhao L, Bakke M, Parker KL (2002) Development of a transgenic green fluorescent protein lineage marker for steroidogenic factor 1. Mol Endocrinol 16:2360-2370.

Tseng GC, Oh MK, Rohlin L, Liao JC, Wong WH (2001) Issues in cDNA microarray analysis: quality filtering, channel normalization, models of variations and assessment of gene effects. Nucleic Acids Res 29:2549-2557.

Urade Y, Oberdick J, Molinar-Rode R, Morgan JI (1991) Precerebellin is a cerebellum-specific protein with similarity to the globular domain of complement C1q B chain. Proc Natl Acad Sci USA 88:1069-1073.

Wishart TB, Walls EK (1975) Water intoxication death following hypothalamic lesions in the rat. Physiol Behav 15:377-379.

Wu W, Wong K, Chen J, Jiang Z, Dupuis S, Wu JY, Rao Y (1999) Directional guidance of neuronal migration in the olfactory system by the protein Slit. Nature 400:331-336.

Yang YH, Dudoit S, Luu P, Lin DM, Peng V, Ngai J, Speed TP (2002) Normalization for cDNA microarray data: a robust composite method addressing single and multiple slide systematic variation. Nucleic Acids Res 30:E15. 